Proc. Indian Acad. Sci. (Earth Planet Sci.), Vol. 90, Number 2, 1981, pp. 173-187.

- Printed in India.

\title{
Rocket measurements of ozone concentrations in the stratosphere and mesosphere over Thumba
}

\author{
B H SUBBARAYA and SHYAM LAL \\ Physical Research Laboratory, Ahmedabad 380 009, India
}

MS received 17 September 1980; revised 28 May 1981

\begin{abstract}
A rocket-borne solar middle ultraviolet photometer has been developed at the Physical Research Laboratory, Ahmedabad for the measurement of ozone concentrations at stratospheric and mesospheric heights. The instrument has now been flown successfully several times from Thumba and ozone concentrations determined over an altitude range of 15 to $80 \mathrm{~km}$. This paper describes the instrumentation, data analysis technique as well as the laboratory calibration procedures. Also presented are the results from four successful rocket experiments conducted during equinoctial months under an Indo-USSR collaborative programme for strato-mesospheric studies. The results show that at Thumba peak ozone concentrations vary between 2.2 and $3.1 \times 10^{12}$ molecules per cc and the peak altitude varies from 25 to $29 \mathrm{~km}$ from flight to flight. In the altitude region above about $40 \mathrm{~km}$ the ozone concentrations over Thumba are lower than the standard mid-latitude model values, by a factor lying between 1.5 and 2.5 .
\end{abstract}

Keywords. Rocket; ozone; stratosphere; mesosphere.

\section{Introduction}

There has been an upsurge of interest in the study of atmospheric ozone during the last decade as a result of the recognition of the possible depletion of the ozone overburden by several trace constituents such as $\mathrm{NO}_{x}, \mathrm{HO}_{x}$ and $C L O_{x}$ released into the atmosphere by supersonic aircraft, chlorofluoro-methanes from the spraycans and the refrigerants, etc. (Crutzen 1970; Johnston 1971; Molina and Rowland 1974, 1975). While the several studies conducted during the seventies (CIAP 1974; Johnston 1975, 1977; Duewer et al 1977; McElroy 1974, 1977) have not been able to establish beyond doubt that a threat to the ozone overburden exist, it has been recognised that the possibility of ozone depletion as a result of these anthropogenic activities cannot be ruled out. Further, it has been realised that it is first necessary to recognise and delineate the natural variations such as seasonal solar cycle, etc. not only in total ozone but also in its veritcal distribution, before the long term depletion effects can be established. The relative importance of chemistry and dynamics in determining the equilibrium ozone concentrations is altitude dependent, dynamical features controlling the ozone distribution below an altitude of about $30 \mathrm{~km}$, and chemistry becoming dominant

\footnotetext{
This paper is dedicated to the memory of Prof. J. S. Shirke
} 
only at higher altitudes. A systematic monitoring of the ozone distribution above about $30 \mathrm{~km}$ is a major requisite for a study of the ozone depletion problem.

Ground based monitoring by the Dobson, Brewer or the M-83 units gives only total ozone content. The Umkehr technique for obtaining vertical profiles of ozone assumes that there is no variation during the day and also it assumes a specific layer shape. Further, this technique would be unable to detect changes in $\mathrm{O}_{3}$ concentration above about $40 \mathrm{~km}$ with sufficient accuracy since ozone above this altitude constitutes only a few percent of the total content. High-flying balloons generally reach altitudes of about $30 \mathrm{~km}$ only. Rockets and satellites are the only tools for monitoring ozone concentrations at higher altitudes. While satellities can collect data over an extended period of time and can cover the large portion of the globe, the inversion techniques used to obtain ozone profiles are not yet fully established (Krueger et al 1973; Aruga and Igarshi 1976; Frederick et al 1977). Frequently rocket measurements are used for validation of the satellite data. Rockets are still the best tools for obtaining vertical distribution of ozone. A rocket ozonesonde has been developed at the Physical Research Laboratory for measurement of ozone concentration profiles in the stratosphere and mesosphere. The instrument has been flown successfully from Thumba on several types of rockets and has also been used in an international rocket ozonesonde intercomparison conducted at the NASA Wallops Flight Centre during Oct-Nov. 1979. This paper presents the details of the instrumentation, its calibration, data analysis and the results from a series of rocket launchings: conducted under an Indo-USSR collaborative programme.

\section{Instrumentation}

The instrument is based on the strong absorption of solar ultraviolet radiation in the $200-300 \mathrm{~nm}$ wavelength region by the atmospheric ozone. A photometer working at one or more wavelength bands in the above region taken on board a rocket measures the attenuation profile of the solar UV radiation in the particular band (s). Assuming that ozone is the only absorbing agent in the atmosphere for the chosen wavelength band (s) and knowing ozone absorption cross-section, it is possible to determine in situ, the ozone concentration in the atmosphere. This principle has been used for ozone profile measurements by several workers in the past (Krueger and Mc Bride 1968; Weeks et al 1978; Miller and Ryder 1973). A typical instrument is a three-channel photometer working at $250 \mathrm{~nm}, 280 \mathrm{~nm}$, $310 \mathrm{~nm}$, each with a band width of about $10 \mathrm{~nm}$. The three wavelength bands are chosen to lie at the high, low and very low ozone absorption spectrum so. that attenuation due to ozone can be measured for different atmospheric depths and ozone concentrations estimated over a large altitude range. With the above three channels, linder favourable experimental conditions, it is possible to determine ozone concentrations from $15 \mathrm{~km}$ upto an altitude exceeding $70 \mathrm{~km}$. A particular advantage of this technique lies in the fact that the instrument needs no calibration and yields absolute ozone concentrations. The instrument is sufficiently compact, does not make heavy technological demands on the rocket system and can be easily integrated on rockets carrying other instruments for upper atmospheric investigations. 


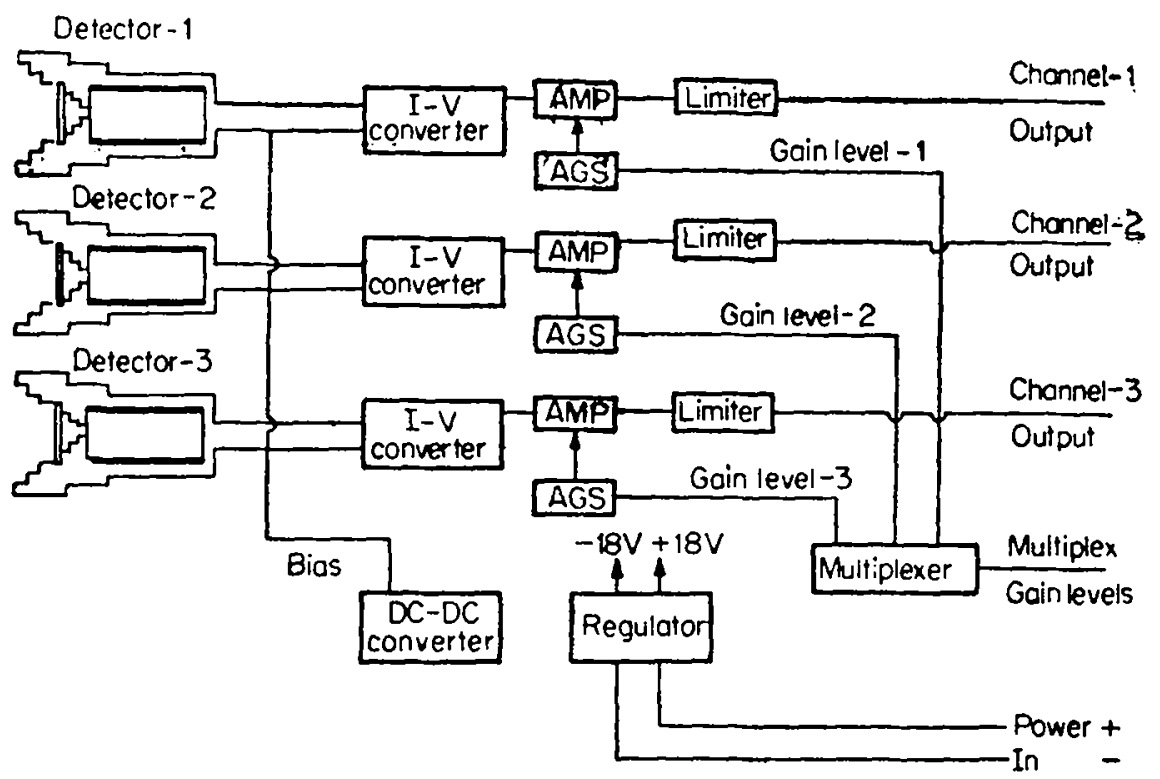

Figure 1. Schematic of the solar MUV photometer.

The instrument consists of three photometers (figure 1), each consisting of an interference filter, solar blind phototube and an electrometer amplifier with automatic gain switching. The interference filter has a bandwidth of about $10 \mathrm{~nm}$ around the central wavelength (which is typically 250,280 and $310 \mathrm{~nm}$ ) and is calibrated in the laboratory before use. The photodiode is a solar-blind UV sensitive photodiode (Hamamatsu HTV 765), with a nearly uniform response in the $200-290 \mathrm{~nm}$ region. The response starts falling around $290 \mathrm{~nm}$ and there is a sharp cut-off at $320 \mathrm{~nm}$. The diode is operated in the short circuit mode at a suitable bias to obtain linear response between the input radiation flux and output current. The photodiode current is fed to the inverting input of a low leakage operational amplfier (Intersil 8007 MTV or BEL 536) and the resulting voltage output which is directly proportional to the photodiode current and hence the incident radiation flux, is measured by means of an amplifier with automatic gain switching. This arrangement gives the instrument a linear response over a dynamic range of three decades of incoming radiation flux. The instrument is built in two packages, the first package is the detector assembly which houses the interference filters, photodiodes and the electrometer amplifiers. The interference filterphotodiode assembly is housed in a brass housing, anodised black and with a stepped front, so as to minimise internal reflection, and scattered radiations from falling on the photodiode. The detector assembly is mounted in the instrument section at a suitable angle so that it can look at the sun once every rocket spin (figure 2). A suitable look window is provided on the rocket spin, by opening a door at a pre-determined time after the rock et take-off. 


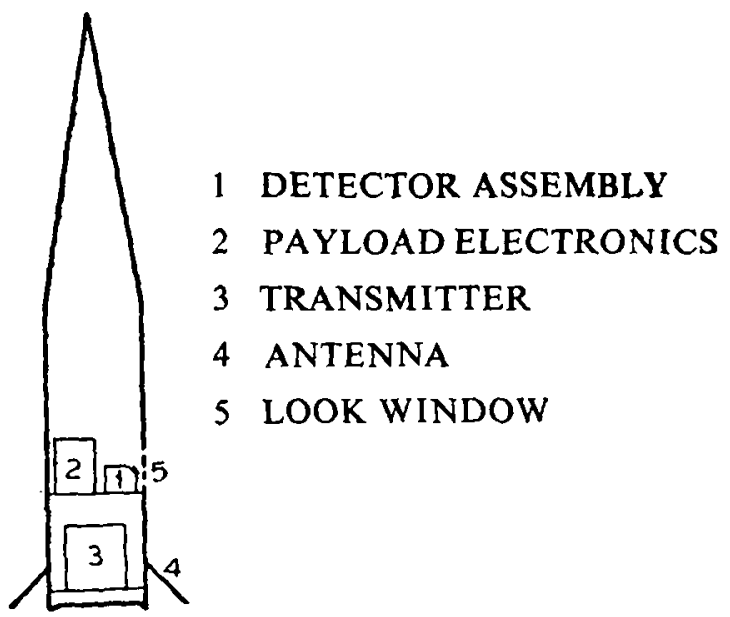

Figure 2. Rocket ozonesonde assembly.

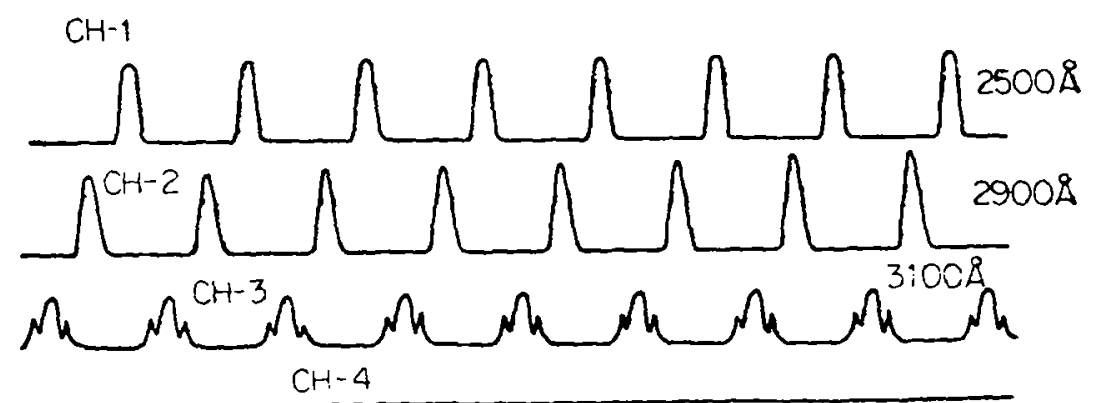

CH- 5

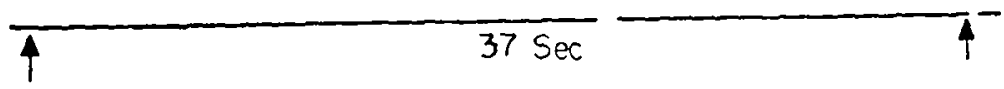

Figure 3. A sample of the real time telemetry chart illustrating the nature of the instrument signals.

\section{Data analysis and instrument calibration}

\subsection{Data reading and smoothing}

During flight, the instrument looks at the sun once every spin cycle. The detector output is, therefore, in the form of pulses (figure 3). The instrument signals are recorded on high speed paper chart at 10 inches/sec as well as on tape. The data can be read manually from the paper chart or if more accurate data reading 
is required, the data on tape can be digitised and read on an IBM computer. The detector output is a function of the incident radiation flux as well as the orientation of the detector axis with respect to the sun. An onboard solar aspect sensor monitors the aspect angle during the flight and the instrument signals are corrected for variations in this angle and adjusted for normal incidence. The correction factor is a product of the filter transmission as well as the geometrical factor of the instrument and is determined in the laboratory before flight for each instrument. The aspect corrected data is subjected to a 5-point running average to remove small scatter in the data points. Since the average spin frequency of the rocket is 5 cycles/sec this gives a height resolution of $1 \mathrm{~km}$. The actual photometer is capable of a much higher frequency response (nearly 1 $\mathrm{kHz}$ ). When flown on a stabilised sun-seeking platform, so that the photometer is continuously looking at the sun, a height resolution of 10 meters can be achieved.

\subsection{Transmission function of the interference filters and angular response of the detector}

The transmission characteristics of the interference filters are determined in the laboratory before flight using a Beckmann DK2A spectrophotometer. It is preferable to determine these characteristics several times before flight at intervals of a month or so to ensure that the filters have stable characteristics. It is. quite common for filters in this wavelength range to show up secondary transmission at wavelengths well beyond the specified limits. Such samples will have to be rejected. Typical transmission for some of the filters used in the experiments described here is shown in figure 4.

Another important characteristic is the angular response of filter. It is the well-known that for a multi-layer dielectric interference filter, the transmission

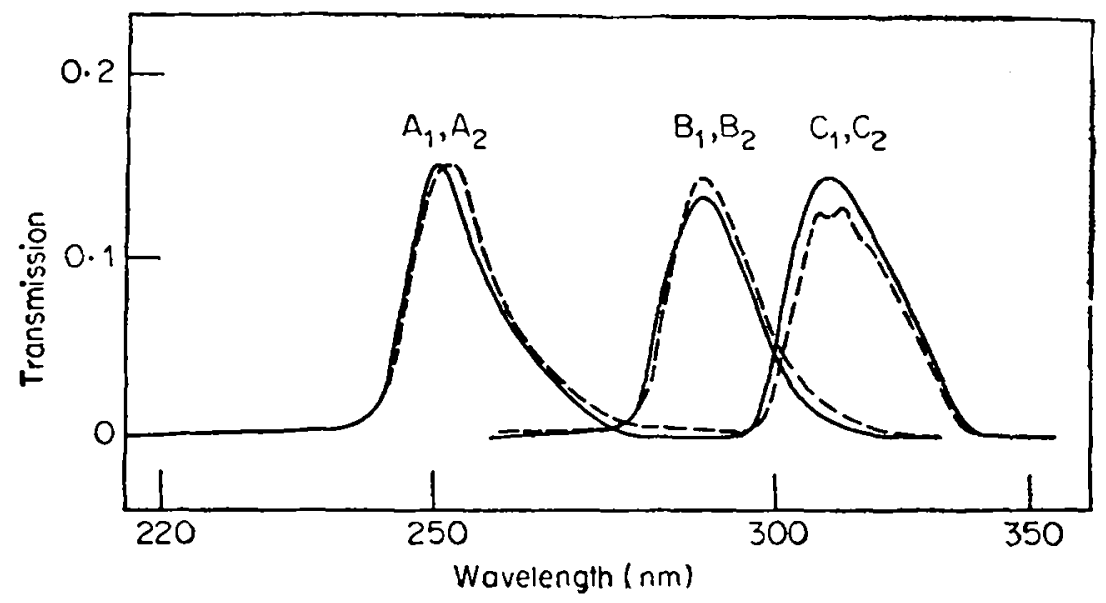

Figure 4. Typical transmission characteristics of the interference filters. $\left(A_{1}, A_{2}\right),\left(B_{1}, B_{2}\right)$ and $\left(C_{1}, C_{2}\right)$ are the characteristic curves for two separate filters in each of the three wavelength bands. 


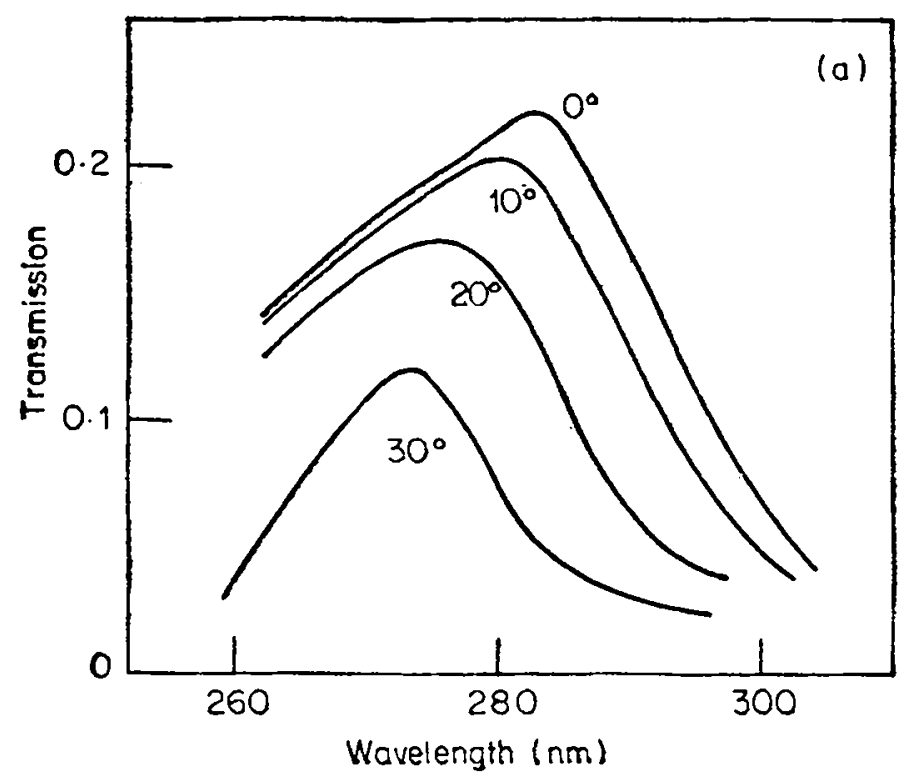

Figure 5. (a) Typical angular response of an interference filter.

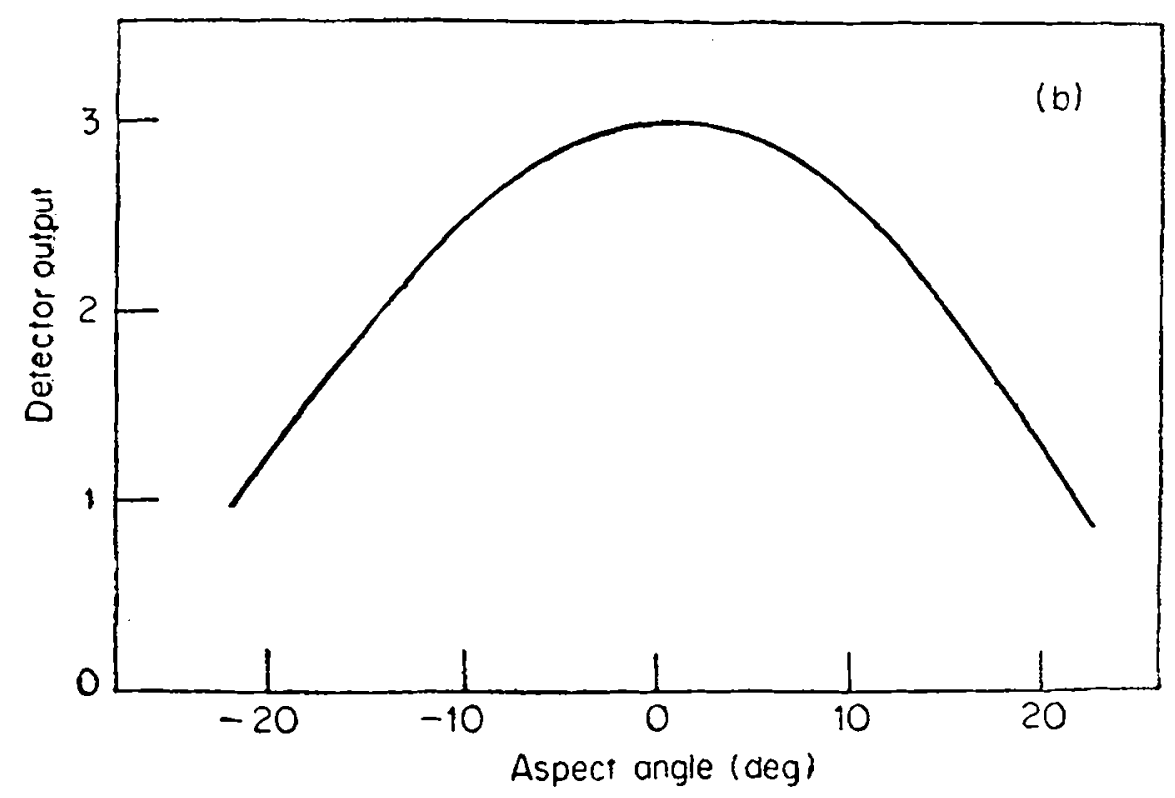

Figure 5. (b) Angular response of the photometer. 


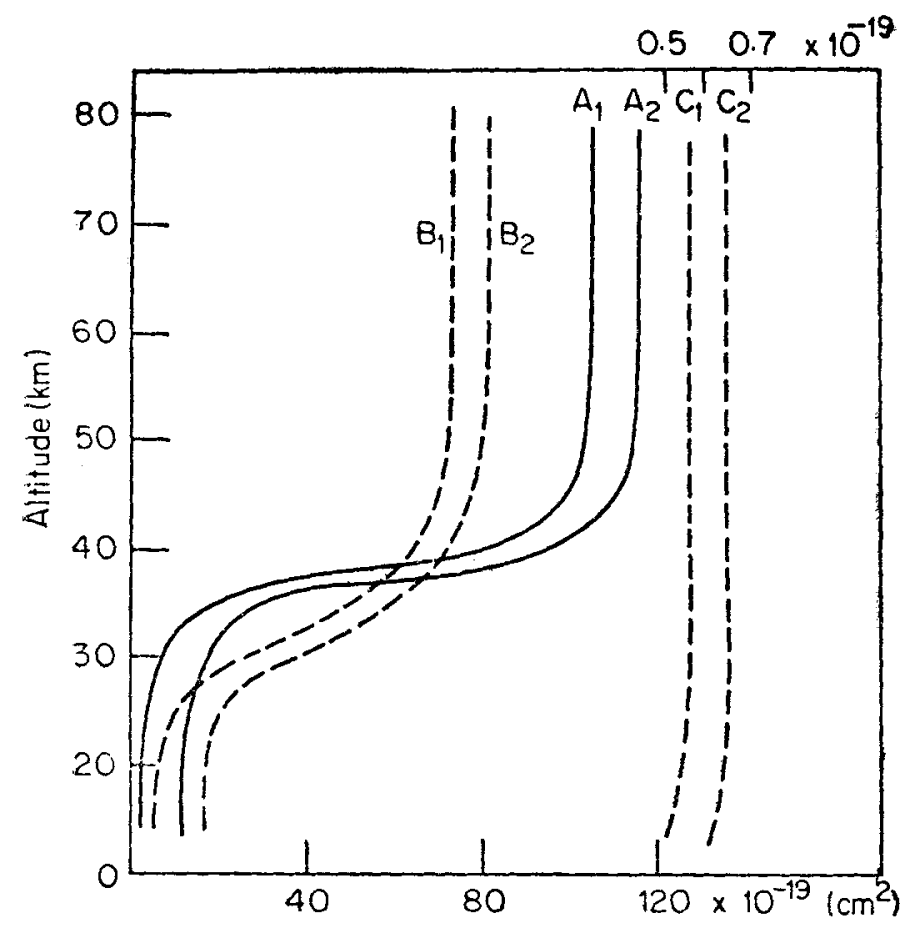

Figure 6. Typical $\sigma_{e f f}(Z)$ curves for the $250 \mathrm{~nm},\left(A_{1}, A_{2}\right) 280 \mathrm{~nm}\left(B_{1}, B_{2}\right)$ and $310 \mathrm{~nm}^{\prime}\left(C_{1}, C_{2}\right)$ channels. The scale is shifted by 10 units from curve 1 to curve 2 for the $250\left(A_{1}, A_{2}\right)$ and $280\left(B_{1}, B_{2}\right) \mathrm{nm}$ filters and by 0.1 unit, for the $310 \mathrm{~nm}$ filters $\left(C_{1}, C_{2}\right)$. Bottom scale is to be used for the $250 \mathrm{~nm}$ and $280 \mathrm{~nm}$ filters and the top scale is to be used for the $310 \mathrm{~nm}$ filters. Note that for the $280 \mathrm{~nm}$ filters $\left(B_{1}, B_{2}\right) 2 \sigma_{\text {off }}(Z)$ is plotted rather than $\sigma_{\theta f f}(Z)$.

characteristic changes with the incident angle. Not only the percentage transmission but also the spectral response changes with change in incident angle. The actual angular response of the instrument is a product of the angular response of the filter and geometry factor of the instrument. Figure 5 shows the typical angular response of an interference filter and figure 6 is the angular response of the MUV photometer obtained in the laboratory. Sometimes, it is possible to verify this response function during a rocket flight when the photometer is well above the absorbing layer, e. g. for the $310 \mathrm{~nm}$ channel at altitudes above about 40 or $50 \mathrm{~km}$ when the observed variations in detector current within a few kilometres are mostly due to variations in aspect angle.

\section{$3 \cdot 3$ Calculation of ozone concentration}

According to Beer-Lambert law, the attenuation of a monochromatic radiation of wavelength $\lambda$, passing from the top of the atmosphere to a height $Z$ in the earth's atmosphere is given by 
$\phi(\lambda, Z)=\phi_{\infty}(\lambda) \cdot \exp \{-\sigma(\lambda) \cdot N(Z)\}$,

where $\phi(\lambda, Z)=$ solar radiation flux at the height $Z$ at wavelength $\lambda\left(\mathrm{cm}^{-2} \mathrm{sec}^{-1}\right)$,

$\phi_{\infty}(\lambda)=$ solar radiation flux at the top of the atmosphere at wavelength $\lambda\left(\mathrm{cm}^{-2} \mathrm{sec}^{-1}\right)$,

$\sigma(\lambda)=$ ozone absorption cross-section at wavelength $\lambda\left(\mathrm{cm}^{2}\right)$,

$N(Z)=$ integrated ozone vertical column density traversed by the ray while passing from the top of the atmosphere to $Z$.

$$
N(Z)=\int_{Z}^{\infty} n\left(O_{3}, Z\right) . F(Z, \chi) d Z
$$

where $n\left(O_{3}, Z\right)=$ ozone number density at an altitude $Z$ and $F(Z, X)=$ Optical depth factor at the altitude $Z$ which is a function of the solar zenith angle. For zenith angles $X<70^{\circ}$, the flat earth approximation is valid and the approximation $F(Z, X)=\sec X$ is valid to within a fraction of a percent (Chapman 1931). For zenith angles larger than about $70^{\circ}$ the curvature of the earth as well as refraction effects need to be considered. Several useful approximations have been formulated in literature (Chapman 1931; Swider 1964; Weeks and Smith 1968). Weeks and Smith's expression

$$
\begin{aligned}
& F(Z, X)=\left\{\frac{\pi(R+h)}{2 H}\right\} \times\left\{1-\operatorname{erf}\left[\frac{90-\chi}{H^{1 / 2}}\right]\right\} \\
& \times \exp \frac{(90-\chi)^{2}}{H}
\end{aligned}
$$

where $H$ is the scale height, $R$ is the radius of the earth, $h$ is the point of nearest approach for a solar ray reaching the altitude $Z$ and erf $(n)$ is the error function, is found very convenient in practice. From (1) and (2)

$$
n\left(O_{2}, Z\right)=\frac{1}{\sigma(\lambda) \cdot F(\bar{Z}, X)} \frac{1}{\phi(\lambda, Z)} \frac{d \phi(\lambda, Z)}{d Z},
$$

Since the photometer is sensitive to a range of wavelengths and since the photometer current is directly proportional to the incident radiation flux in the passband of the photometer expression (4) can be written as

$$
n\left(O_{3}, Z\right)=\frac{1}{\sigma_{\text {off }}(z) \cdot F(z, X)} \frac{1}{I(Z)} \frac{d I(z)}{d Z}
$$

where $I(Z)=$ photometer current at altitude $Z$, and $\sigma_{\text {off }}(Z)=$ effective ozone absorption cross-section for solar radiation in the passband of the detector at the altitude $Z$. 


$$
\sigma_{\text {eff }}(Z)=\frac{\int_{\lambda_{1}}^{\lambda_{2}} \tau(\lambda) \cdot \eta(\lambda) \cdot \sigma(\lambda) \cdot \phi(\lambda, Z) \cdot d \lambda}{\int_{\lambda_{1}}^{\lambda_{2}} \tau(\lambda) \cdot \eta(\lambda) \cdot \phi(\lambda, Z) \cdot d \lambda}
$$

where $\tau(\lambda)=$ transmission of the interference filter at wavelength $\lambda$, $\eta(\lambda)=$ efficiency of the detector at wavelength $\lambda$.

In principle, it is possible to include a Rayleigh scattering term in (1). However, the effect is significant only at altitudes below about $25 \mathrm{~km}$ and for large solar zenith angles when the slant optical paths become large.

\subsection{Effective absorption cross-section}

The effective absorption cross-section given by (6) above, turns out to be altitude dependent. $\sigma_{\text {off }}$ decreases with decrease in altitude. This is because radiations with larger cross-section for ozone absorption are absorbed at higher altitudes and only the radiations for which the absorption cross-sections are smaller pene. trate to lower levels. Computation of $\sigma_{\theta f f}(Z)$ requires a knowledge of the solar spectrum $\phi_{\infty}(\lambda)$, the ozone absorption cross-section $\sigma(\lambda)$ in the pass band of the detector, filter transmission $\tau(\lambda)$ and the photodiode efficiency $\eta(\lambda)$ which is a standard function, is obtained from the manufacturer. Filter transmission is known from laboratory calibration (see $\$ 3.2$ ). We adopt the standard solar flux values of Broadfoot (1972) and the Inn and Tanaka (1953) values for ozone absorption cross-sections. We note that the ozone

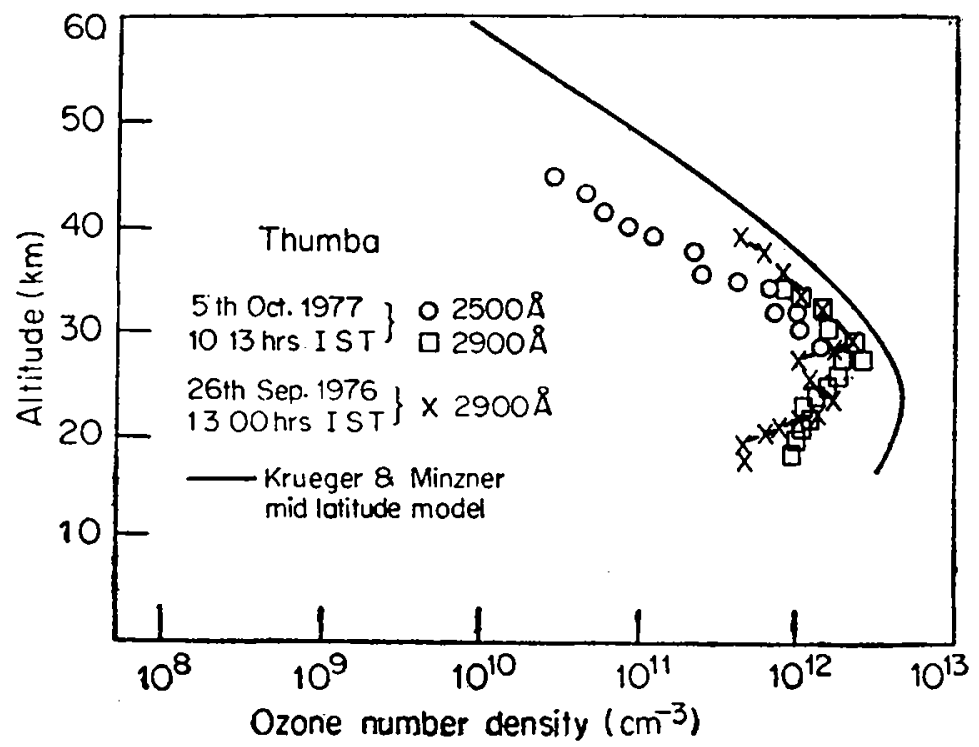

Figure 7. Ozone concentration profiles obtained on 26 September 1976 and 5 October 1977 from Thumba. 
absorption cross sections could be temperature-dependent (Vigroux 1953). Further, computation of $\sigma_{\text {eff }}(Z)$ needs a knowledge of the vertical ozone distribution. A profile adopted for low latitudes from Krueger and Minzner (1976) standard mid-latitude model is used in the computations. Figure 7 shows typical $\sigma_{\text {eff }}(Z)$ profiles. The $\sigma_{\text {eff }}$ values are largely insensitive to the choice of the initial ozone distribution except at the lower-most altitudes of utility of a given detector. Since the effective absorption cross-section at low altitudes is very sensitive to changes in the ozone content above that altitude iteration technique is employed to obtain the final $\sigma_{\text {eff }}(Z)$ values. Starting from model values of ozone densities $\sigma_{\text {eff }}(Z)$ is calculated. Ozone densities are estimated using these $\sigma_{\text {off }}$ values and the observed attenuation of radiation. The ozone values so obtained are now introduced in the $\sigma_{\text {erf }}$ calculations to obtain a new set of $\sigma_{\text {eff }}$ values. This process is repeated until at the lowest heights $\sigma_{\text {eff }}$ values and hence the ozone densities converge. The altitude at which the iteration technique becomes necessary depends on the wavelength chosen and very often this happens to be the lowest altitudes at which the penetrating radiation flux in that wavelength band is quite small.

\section{The Thumba experimental programme}

\subsection{Test flights of $1976-77$}

The first test flight for rocket ozone measurement from Thumba was conducted on 26 September 1976 at $1300 \mathrm{hr}$ IST with an M-100 rocket. The instrument was a single-channel photometer and the flight was primarily intended to qualify the instrument for rocket flights and to check in situ, the photometer performance and sensitiveness. The flight was successful and the data could even be analysed for ozone concentrations in the altitude range of 18 to $35 \mathrm{~km}$ (Acharya et al 1979). Following the success of this flight, three more flights were conducted during 1976-77 as a preparatory phase for an Indo-USSR collaborative programme on strato-mesospheric studies. Details of these flights are shown in table 1A. It is seen from this table that ozone data could be obtained from only two flights-the flight of 26 September 1976 (1300 hr IST) and 5 October 1977 (1013 hr IST) On 5 October 1977, flight ozone corcentrations could be calculated in the altitude range 18 to $45 \mathrm{~km}$. At $45 \mathrm{~km}$, the photometer saturated and further data was not useful for estimation of ozone concentrations. The data of 29 September 1976 is less reliable than that of 5 October 1977 because of the non-availability of data from solar aspect sensor and the aspect angle had to be determined in an indirect manner. Preliminary results obtained from these two flights by analysing the data with an effective height independent cross-section were presented earlier (Subbaraya and Shyam Lal 1978). The discussion of $\S 2$ shows that this can lead to an incorrect estimation of ozone concentrations. Here, the data from these flights is reanalysed using the altitude dependent cross-sections as described in $\S 2$ and using a more realistic correction factor for aspect angle. These results are shown in figure 7 . The ozone profile of 29 September 1976 shows a pronounced double layered structure around the peak, with the maximum value of $2.2 \times 10^{12} / \mathrm{cc}$ being.reached at $29 \mathrm{~km}$. The 
5 October 1977 profile is relatively smoother, the ozone maximhm is reached at $28 \mathrm{~km}$ and the maximum value is $2.4 \times 10^{12} / \mathrm{cc}$.

Table 1. Rocket ozonesonde flights from Thumba.

A. Test flights

1. 26 September 1976 $1300 \mathrm{hr}$ IST.

2. 1 June 1977

1315 hr IST

3. 28 September 1977 $1013 \mathrm{hr}$ IST $1000 \mathrm{hr}$ IST

4. 5 October 1977
Same as above.

Single channel ozone photometer

Double channel ozone photometer.

Double channel ozone photometer. Lymanalpha photometer, solar aspect sensor.
Satisfactory. Ozone concentrations could be estimated from 18 to $35 \mathrm{~km}$. No supporting ozonesonde or $\mathrm{Um}$ kehr measurements are available.

Delay in door release. Instrument exposed to sun only above $50 \mathrm{~km}$. No useful data obtained.

Large coning of rocket and poor signal-to-noise ratio in telemetry. Ozone concentrations could not be determined. Trivandrum ozonesonde data available.

Performance satisfactory. Ozone concentrations obtained in the 19 to 45 $\mathrm{km}$ altitude range. Ozonesonde and Umkehr observations not available.

Good data obtained from $15 \mathrm{~km}$ to $65 \mathrm{~km}$. Ozonesonde data available. meter, solar aspect sensor.

2. 17 April 1979 $1532 \mathrm{hr}$ IST

Three channel photometer, solar aspect sensor.

3. 16 May 1979 1515 hr IST

Three channel photometer, solar aspect sensor.

Three channel photometer, solar aspect

\begin{abstract}
sensor.
\end{abstract}
No useful data obtained.

Malfunction of door release suspected. Simultaneous shipboard measurements by USSR was planned.

Malfunction of power supply system. No data obtained. Simultaneous shipboard measurement by USSR was planned.

\subsection{Indo-USSR collaborative programme-1979}

The first systematic measurements of ozone concentration in the stratosphere and mesosphere over Thumba using the three channel solar MUV photometer, were undertaken during the year 1979 as part of Indo-USSR collaborative programme on strato-mesospheric studies. Four solar MUV photometers were launched on M-100 rockets from Thumba during April-May-June 1979. Table-1B shows the flight summary. Simultaneous balloon launches were conducted from Trivandrum by the India Meteorological Department for these flights. As seen from the table, good data on ozone concentrations was obtained only on the 9 April and 17 April 1979 flights. On both these flights, data could be obtained as 


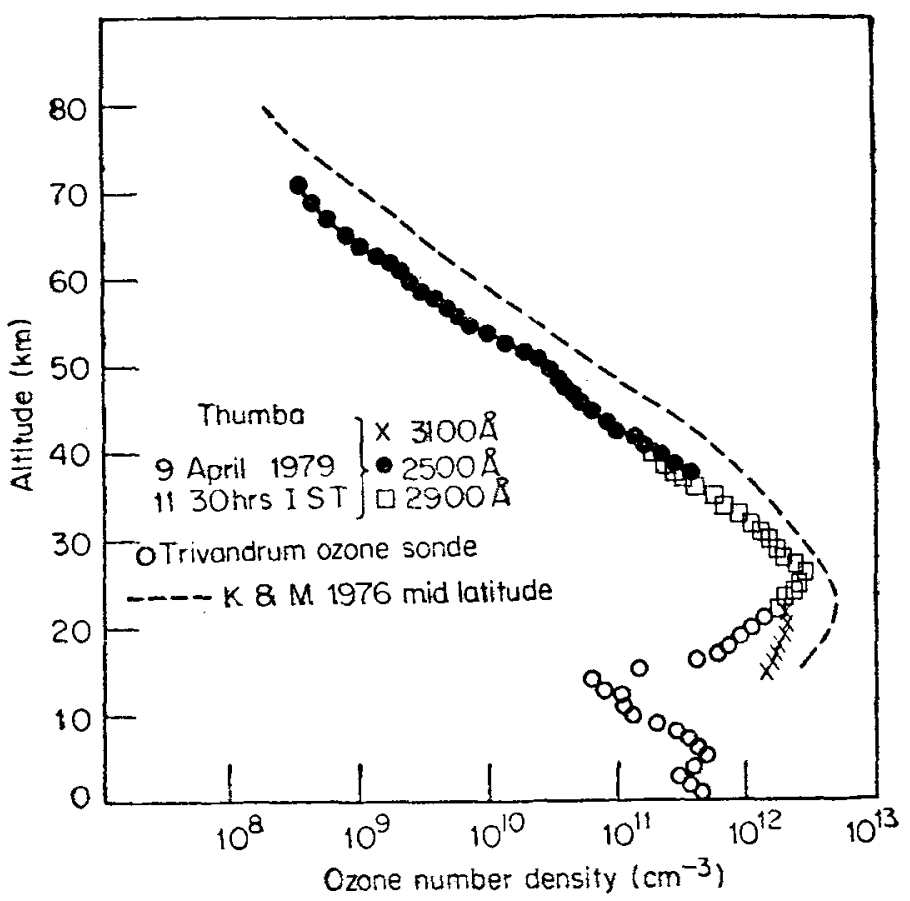

Figure 8. (a) Ozone concentration profiles obtained on 9 April 1979 at $1130 \mathrm{hr}$ IST alongwith midlatitude ozone model of Krueger and Minzner (1976).

soon as the door was released at $15 \mathrm{~km}$ altitude and right upto the rocket apogee. The good quality of the data from the MUV photometer and the solar aspect sensor enabled ozone concentrations to be determined right from $15 \mathrm{~km}$ upto an altitude of $72 \mathrm{~km}$ for the 9 April flight and upto $82 \mathrm{~km}$ for the flight of 17 April 1979. The results are shown in figures $8(a)$ and (b). The $310 \mathrm{~nm}$ channel data yields ozone concentrations upto an altitude of $22-23 \mathrm{~km}$. The $290 \mathrm{~nm}$ channel data yields ozone concentrations from $20 \mathrm{~km}$ to an altitude of $35-40 \mathrm{~km}$. The $250 \mathrm{~nm}$ channel data yields ozone concentration from $35 \mathrm{~km}$ onwards. At altitude above about $35 \mathrm{~km}$, the $310 \mathrm{~nm}$ photometer is well above the absorbing region for that wavelength and its data can be used to supplement the solar aspect sensor for aspect angle variations. There is a slight overlap between the 310 and $290 \mathrm{~nm}$ channels in the $20-24 \mathrm{~km}$ region and between the 290 and $250 \mathrm{~nm}$ channels in the 36 to $40 \mathrm{~km}$ altitude region. In these regions of overlap, the maximum discrepancy between two channels is a factor of 1.5 .

From figures 8 (a) and (b), it is seen that ozone reaches a maximum at $25-26 \mathrm{~km}$ altitude with an interesting sharp nose superimposed on a broad maximum. There are differences both in layer shape as well as in number densities below the altitude of $30 \mathrm{~km}$. The peak value for 9 April is $2.9 \times 10^{12} / \mathrm{cc}$, and occurs at $26 \mathrm{~km}$, while on 17 April, the peak value is $3.1 \times 10^{12} / \mathrm{cc}$ occurring at $25 \mathrm{~km}$. Day-to-day variations in total ozone are well known from ground based Dobson data. The $15-30 \mathrm{~km}$ altitude region around the ozone peak constitutes nearly $50 \%$ of the total ozone, the observed differences between the two flights are not 


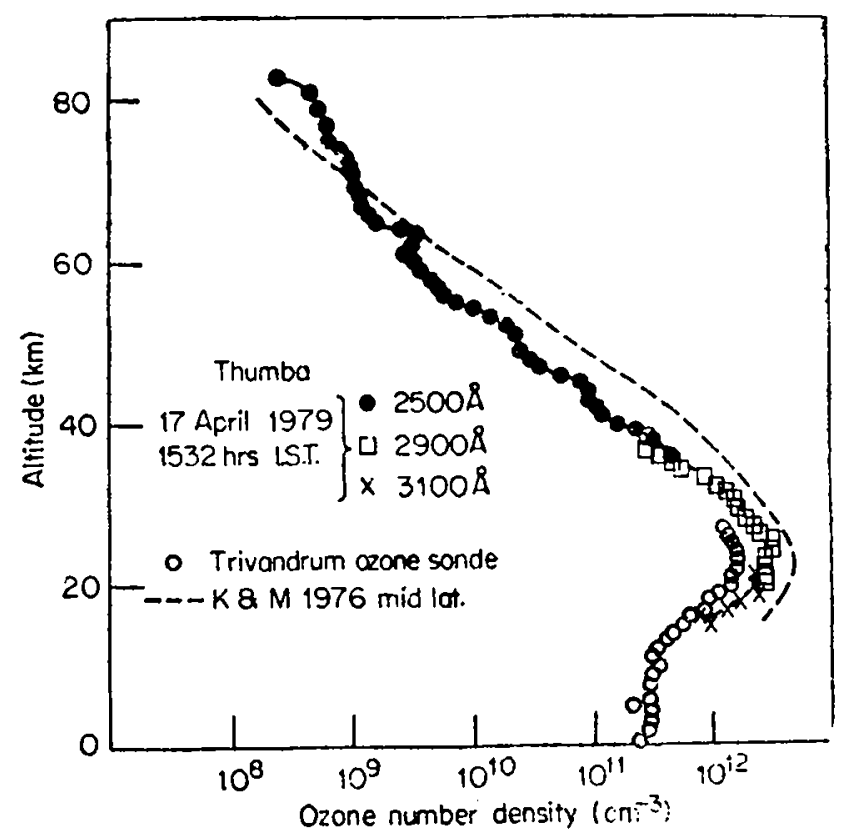

Figure 8 (b) Ozone concentration profiles obtained on 17 April 1979 at 1530 hrs IST alongwith midlatitude ozone model of Krueger and Minzner (1976).

surprising although the photochemical time constants are large at these altitudes. These differences are to be understood more in terms of dynamics than in terms of ozone chemistry (Kulkarni 1968; NAS 75). In the region above the peak, at altitudes of 35 to $50 \mathrm{~km}$ both flights yield similar ozone concentrations. At altitudes above about $60 \mathrm{~km}$ the 17 April flight yields larger values than the 9 April flight and the discrepancy increases with increasing altitudes. The other major feature to be noted is a wave-type perturbation on the 17 April flight above about $40 \mathrm{~km}$. A perturbation of much smaller amplitude is discernible on the 9 April flight. It is interesting to note that the wave-like feature shows up only above the main ozone heating region and is more pronounced on the afternoon profile, after a major portion of the diurnal heat input is accomplished and on a day which as characterised by higher solar and geomagnetic activity.

\section{Discussion}

The four rocket flights which have given ozone profiles over Thumba were all conducted in the equinoctial months. While all the four days were geomagnetically undisturbed, the solar flux levels and the sunspot numbers were different from flight to flight (table 2). The ozone concentration profiles obtained show differences from flight to flight. The profiles of figure 7 show an ozone maximum in the $28-29 \mathrm{~km}$ region with peak concentration of $2.2 \times 10^{12}$ and $2.4 \times 10^{12}$ molecules/cc. The profiles of figure 8 show the ozone maxima in the $25-26 \mathrm{~km}$ 
Table 2. Peck ozone concentrations and the altitude of the peak along with the Solar and Geophysical data for the sucessful rocket flights

\begin{tabular}{|c|c|c|c|c|c|c|c|}
\hline & & $\begin{array}{l}\text { Solar } \\
\text { zenith } \\
\text { angle }\end{array}$ & $\begin{array}{l}\text { Solar } \\
\text { flux } 2800 \\
\text { MHz. }\end{array}$ & $\begin{array}{l}\text { Sunspot } \\
\text { No. } R_{z}\end{array}$ & $\begin{array}{l}A_{p} \\
\text { index }\end{array}$ & $\begin{array}{l}\text { Peak ozone } \\
\text { concent- } \\
\text { ration } \\
\text { molecules/ } \\
\text { cc. }\end{array}$ & $\begin{array}{l}\text { Altitude of } \\
\text { peak ozone } \\
\text { concent- } \\
\text { rations }(\mathrm{km})\end{array}$ \\
\hline & $\begin{array}{l}\text { 26 September } 1976 \\
1360 \mathrm{hr} \text { IST. }\end{array}$ & $615^{\circ}$ & 72.8 & 17 & 13 & $2.2 \times 10^{12}$ & 29 \\
\hline 2. & $\begin{array}{l}5 \text { October } 1977 \\
1013 \mathrm{hr} \text { IST. }\end{array}$ & $32^{\circ}$ & 104 & 38 & 8 & $2.4 \times 10^{12}$ & 28 \\
\hline 3. & $\begin{array}{l}9 \text { April } 1979 \\
1130 \mathrm{hr} \text { IST. }\end{array}$ & $15^{\circ}$ & 169.6 & 61 & 9 & $2.9 \times 10^{12}$ & 26 \\
\hline 4. & $\begin{array}{l}17 \text { April } 1979 \\
1532 \text { hr IST. }\end{array}$ & $47^{\circ}$ & 168 & 107 & 11 & $3.1 \times 10^{12}$ & 25 \\
\hline
\end{tabular}

region with peak values of $2.9 \times 10^{12}$ and $3.1 \times 10^{12}$ molecules/cc. While this shows a considerable variability in the vertical ozone distribution over Thumba, it is not yet clear whether there exist any systematic features in the variability. In the altitude region above about $35 \mathrm{~km}$, all the profiles show similar shapes and scale heights. However, the afternoon profile shows larger ozone concentrations and larger scale heights above about $50 \mathrm{~km}$. A wave-like perturbation which is quite pronounced can also be seen on the afternoon profile. The ozone concentration of figures 7 and 8 show smaller ozone concentrations at all altitudes when compared to the midlatitude model ozone profile of Krueger and Minzner (1976). The peak values are lower by factors lying between 1.6 and 2.3 for the different flights. In the $40-70 \mathrm{~km}$ region, the values are lower than the mid-latitude values by a factor of about $2 \cdot 5$. Both ground based as well as satellite studie show that the total ozone over low latitudes; is much less than that over midlatitudes, hesser by a factor of about 1.6 (London 1967, Hilsenrath et al 1980). It is not clear whether the difference between the Thumba profiles and the midlatitude model profile is a simple consequence of this decreased total ozone overburden in the tropics or whether there are additional contributions due to differences in the other atmospheric minor constituents that play a role in determining the ozone distribution.

\section{Acknowledgements}

Messrs Y B Acharya and R N Misra were associated with several phases of the instrument design. Most of the payload fabrication and testing was done by Messrs J T Vinchi and S K Banerjee. The rocket flights reported in this paper were conducted under an Indo-USSR collaborative programme with Prof. P D Bhavsar and Dr A V Fedynski as Scientific co-ordinators. Acknowledgements are also due to Prof. J S Shirke and Dr C A Reddy, members of the Indo-USSR collaborative programme on strato-mesospheric studies for working out the 
details of the programme. The actual rocket launchings were facilitated by the cooperation and support of the Rohini Sounding Rocket Division at Thumba Data reading and analysis were done by Messrs $R$ I Patel and K S Patel. Dr V Narayanan was responsible for arrangement with the India Meteorology Department of the balloon ozonesonde ascents from Trivandrum. Many of the interference filters used in the experiments were calibrated at the Department of Chemistry, Sardar Patel University, Vallabh Vidyanagar, Anand, with the kind courtesy of Prof. K C Patel to whom grateful acknowledgements are due.

\section{References}

Acharya Y B, Misra R N, Shyam Lal and Subbaraya B H 1979 J. Inst. Elec. Telecom. Eng. 25254

Aruga T and Igarashi T $1976 \mathrm{Appl}$. Opt. 15261

Broadfoot A L 1972 Astrophys. J. 173681

Chapman S 1931 Proc. Phys. Soc. 43 26, 483

CIAP Monograph 11974 DOT-TSS-75-51 Department of Transportation, Federal Aviation Administration, Washington DC USA

Crutzen P J 1970 Q. J. R. Meteor. Soc. 96320

Duewer W H, Wuebbles D J, Ellsasser H W and Chang J S 1977 J. Geophys. Res. 82935

Frederick J E, Hays P B, Guenther B E and Heath D F 1977 J. Atmos. Sci. 34637

Hilsenrath E, Heath D and Schlesinger B 1980 J. Geophys. Res. 856969

Inn E C and Tanaka Y 1953 Opt. Soc. Am. 43870

Johnston H S 1971 Science 173517

Johnston H S 1975 Rev. Geophys. Space Sci. 13637

Johnston H S 1977 J. Geophys. Res. 821767

Krueger A J and McBride W R 1968 Naval Weapons Cent. Rep. TP 4512

Krueger A J, Heath D F and Mateer C L 1973 Pure Appl. Geophys. 1061254

Krueger A J and Minzner R A 1976 J. Geophys. Res. 814477

Kulkarni R N 1968 Tellus 20305

London J 1967 Space Res. 7172

McElroy M B, Wofsy S C, Penner J E and McConnell J C 1974 J. Atmos. Sci. 31287

McElroy M B, Wofsy S C and Young Y L 1977 Philos. Trans. R. Soc. (London) B277 159

Miller D E and Ryder P. 1973 Planet. Space Sci. 21963

Mitra A P 1977 Minor constitutents in the middle atmosphere ISRO-INCOSPAR Science Report-03-77, ISRO Bangalore

Mitra A P 1980 Proc Indian Natl. Sci. Acad. 46198

Molina M J and Rowland F S 1974 Nature (London) 249810

Molina M J and Rowland F S 1975 Rev. Geophys. Space Phys. 131

Nicolet M 1975 Rev. Geophys. Space Phys. 13593

Panel on atmospheric physics and chemistry-stratospheric ozone and its photochemistry in environmental impact of stratospheric flight 1975 Washington DC : National Academy of Sciences

Sasi M N and Sen Gupta K 1979 VSSC Technical Report VSSC TR. 4615779

Subbaraya B H and Shyam Lal 1978 Paper presented at COSPAR Innsbruck

Swider W 1964 Planet. Space Sci. 12761

Vigroux 1953 Ann. Phys. Ser. 12118709

Weeks L H and Smith L G 1968 J. Geophys. Res. 734835

Weeks L H, Good R E, Randhawa J S and Trunks H 1978 J. Geophys. Res. 83978 